\title{
PROYECTOS FAMILIARES Y MIGRACIONES EN EUROPA OCCIDENTAL DURANTE LA ÉPOCA CONTEMPORÁNEA
}

\author{
JUAN LUIS CARRELLÁN \\ UNIVERSIDAD DE CÓRDOBA
}

\author{
PaOla García \\ UNIVERSITÉ PARIS NANTERRE
}

Los estudios migratorios recientes desarrollados por las historiografías europeas y americanas están poniendo de relieve la importancia del papel de la familia en el proceso migratorio.

El actor de referencia ya no es sólo y exclusivamente el individuo, como postula la teoría neoclásica ${ }^{1}$ de las migraciones que desde la perspectiva microeconómica considera la migración como el resultado de una decisión individual basada en criterios económicos racionales, sino que la familia se convierte en el elemento clave de comprensión del fenómeno migratorio. En los años noventa una serie de trabajos que se inscriben en la corriente de pensamiento de la Nueva Economía de las Migraciones ${ }^{2}$, ofrecen nuevas perspectivas teóricas. Los investigadores analizan la decisión de emigrar a partir de lógicas y dinámicas colectivas ya sean familiares y/o comunitarias. La familia se convierte entonces en el espacio privilegiado desde donde se elabora y construye la estrategia de la emigración de sus miembros. La decisión de emigrar se toma dentro de la unidad familiar con el fin de maximizar sus ingresos y diversificar sus fuentes de financiación a la vez que se minimizan los riesgos relacionados con la experiencia migratoria. La unidad familiar es la que asume la decisión de la emigración y luego se convierte en una intensa red de comunicación que se establece entre el que se ha marchado y los que se han quedado. Posteriormente si el emigrante consigue estabilizar su situación económica y responder a los requisitos legales, puede producirse una reunión con otros miembros de la familia en el destino final o, en caso contrario, el proceso puede revertirse y el emigrante vuelve al punto de partida. El cambio de perspectiva analítica que supone considerar las lógicas familiares como elemento clave de la experiencia migratoria ha permitido a lo largo de estos últimos años abarcar la problemática de la migración a partir de aproximaciones nuevas relacionadas con la noción

\footnotetext{
${ }^{1}$ HARRIS J. R. et TODARO M.P.: "Migration, unemployment and development: A two-sector analysis", American Economic Review, no 60/1 (1970), pp. 126-142.

2 STARK, Oded: "Discontinuity and the theory of international migration", Kylos, no 37/2 (1984), pp. $206-222$
} 
de red $^{3}$, la perspectiva de género ${ }^{4}$ y las dinámicas transnacionales 5 .

Este número busca profundizar la relación entre familia y migración, temática que ha tenido un desarrollo dentro de la historia social por el impulso efectuado por investigadores de las ciencias sociales como historiadores, sociólogos y antropólogos formando redes nacionales y transnacionales, importantes grupos de investigación y congresos regulares por todo el mundo. Además habría que mencionar las innumerables tesis de máster y doctorado y los numerosos artículos científicos que abordan el tema que parece no agotarse. Atendiendo este interés y destacando la importancia que está adquiriendo la temática hemos considerado oportuno aportar una serie de trabajos de diversos autores que analizan el fenómeno migratorio teniendo a la familia como eje vertebrador en trabajos que sitúan a países de la Europa occidental (Francia, España e Italia) en el centro de sus investigaciones. Pensamos que este dossier es una buena manera de presentar estos resultados de investigación y de poner en perspectiva nuevas formas de abordar este tema.

De esta manera, contamos con el estudio de Santiago de Miguel Salanova "Movilidad en familia y movilidad individual hacia la gran ciudad. Estrategias de inserción residencial y laboral en Madrid, 1880-1905" en el que relaciona los procesos de inserción laboral y las redes familiares, además de contribuir a la compresión de las experiencias de vida, centrándose como telón de fondo en la inmigración a Madrid durante el período comprendido entre 1880 y 1905. Otra de las propuestas es el análisis de Ina Niang Medina con el trabajo "Le projet migratoire des Sénégalais vers la France: une élaboration individuelle et/ou collective" que pretende comprender el papel de la familia en la decisión de que algunos de sus miembros se conviertan en migrante. Para ello se ha centrado en recopilar información en el seno de las familias de la capital senegalesa que tienen algún familiar en Francia. Estudia el rol que ocupa el migrante en el marco familiar y social así como sus objetivos en el desarrollo del proceso migratorio y sus deseos de regresar o no a Senegal después de valorar su experiencia en Francia. Siguiendo con esta mirada de los inmigrantes en Francia, Yacine Alahyane con su artículo "Migration sans la famille et construction de l'espace familial en situation de contrainte. Le cas des personnes âgées nées en Afrique du Nord-Ouest et résidant en France" que como su nombre indica tiene el objetivo de analizar la construcción del espacio familiar en los ancianos nacidos en el norte y el oeste de África y

\footnotetext{
3 MASSEY, D.: "Social structure, household strategies, and the cumulative causation of migration", Population Index, no 56/1 (1990), pp. 3-26.

4 SASSEN S.: "Women's burden: counter-geographies of globalization and the feminization of survival", Journal of International Affairs, no 53/2 (2000), pp. 503-524.

${ }^{5}$ SCHILLER N.G, BASCH L., BLANC-SZANTON, C.: "Transnationalism: a new analytic framework for understanding migration", Annals of the New York Academy of Sciences, no 645/1 (1992), pp. 1-24.
} 
que residen en Francia, mediante la trayectoria individual y familiar mostrando las restricciones y las estrategias espaciales. Además se muestra cómo esta situación impacta a la familia en su configuración espacial, organización y relaciones con el espacio.

Por otra parte, contamos con el estudio de Adelina Miranda "Recompositions familiales en situations migratoires" que analiza los sujetos de la familia (migrantes y no migrantes, asentados y transitorios) vinculados a sus interacciones en los ámbitos económicos, culturales, sociales y legales principalmente. En este sentido, la autora observa que no hay isomorfismo entre las estructuras de parentesco y las formas migratorias y que es fundamental tener en cuenta la simultaneidad de varios modelos familiares en las mismas configuraciones migratorias. Finalmente, Beatriz Collantes en su artículo "La invisibilización de las mujeres en los estudios de los procesos migratorios" insiste en la necesidad de considerar a las mujeres como sujetos activos de la experiencia migratoria y sugiere que el introducir la perspectiva de género en el análisis puede permitir desarrollar políticas públicas que ayuden a remediar las causas que provocan las migraciones de las mujeres. 